\title{
Teatro e história: a incrível dialética entre processos sociais e formas sensiveis
}

Theatre and History: the astonishing dialectic between social processes and sensible forms

Fernando Kinas ${ }^{1}$ 


\section{Resumo}

Contra a hipótese idealista e pouco preocupada com as urgências sociais, este artigo argumenta sobre as relações inextricáveis entre teatro, história e política. Ele destaca ainda a centralidade da construção do sentido, portanto, da inteligibilidade, como instrumento para a ação teatral.

Palavras-chave: Teatro contemporâneo; teatro político; teatro e história; dialética

\section{Abstract}

Against the idealistic hypothesis and little concerned with social emergencies, this article argues about the inextricable links between theater, history and politics. It also emphasizes the centrality of the construction of sense, therefore, intelligibility, as a tool for the theatrical action.

Keywords: Contemporary theater; political theater; theater and history; dialectic

ISSN: 1414.5731

E-ISSN: 2358.6958

${ }^{1}$ Diretor e pesquisador teatral. Doutor em Teatro pela Universidade Sorbonne Nouvelle (Paris 3) e Universidade de São Paulo (USP). 


\section{HISTÓRIA E POLÍTICA}

Para iniciar uma discussão produtiva sobre teatro e política é importante fazer algumas observações gerais antes de entrar no vivo do assunto, que examina certas opções e manifestações do teatro contemporâneo. Esta tarefa se impõe não em função de exigências acadêmicas ou veleidades intelectuais, mas porque diante da atualidade - teatral e política - há urgência em clarificar as questões e assumir um ponto de vista.

Em outro momento já abordei, sumariamente, a chamada "vocação política do teatro" (Kinas, 2013a, p. 31). Convém insistir na discussão e, no âmbito deste texto, tentar esclarecer o tema espinhoso. Novamente me socorro em Bernard Dort, desta vez deixando correr um pouco mais a citação. Peço paciência aos que já estão familiarizados com o tema, para quem a argumentação talvez soe redundante:

Quando se fala em teatro político, pensa-se em teatro engajado, teatro didático, tomada de posição. Creio que isso é colocar mal o problema, ou, em todo caso, restringi-lo de maneira abusiva. É preciso não esquecer: 'político', em sua acepção mais ampla, designa tudo 'o que se relaciona com os interesses públicos' e por teatro é preciso entender não apenas a obra dramática e seu conteúdo, mas também a peça tal como é representada diante de um certo público e para um certo público - a obra e sua forma cênica. A partir daí, tudo muda: a interrogação não se aplica mais unicamente às 'mensagens' deste ou daquele autor dramático, mas abrange todo o teatro no coração mesmo de seu exercício (Dort, 1977, p. 365).

O texto em questão é $A$ vocação política, um clássico da reflexão teatral, escrito em 1965 pelo primeiro grande teórico do brechtismo na França. A sequência da citação talvez seja seu trecho mais conhecido, e também o mais eloquente:

Em vez de ficarmos nos perguntando como o teatro pode ser político, não seria melhor refletir sobre o fato de que, de alguma maneira, o teatro sempre é político, ontologicamente? E falar de uma vocação política do teatro. Nestes termos, a questão não seria mais saber qual poderia ser, em determinadas circunstâncias, a eficácia desta ou daquela obra dramática, mas estabelecer, claramente, a dimensão própria a todo grande teatro - ficando apenas por avaliar, posteriormente, de que modo autores e encenadores, nos dias de hoje, aceitam ou recusam tal dimensão (Dort, 1977, p. 366).

Mesmo dando algum desconto, que o momento histórico em que o texto foi escrito nos autoriza (não só pelo calor de uma época que explodiria com todas as suas cores em maio de 1968, mas também porque o autor não tinha como antecipar os tempos ditos pós-modernos que produziram um novo tipo teatro, abusivamente chamado de pós-dramático), e mesmo considerando peculiaridades do teatro francês, como um textocentrismo renitente (por mais que se afirme o contrário, como é o caso de Dort), há algo de canônico nestas formulações, temperadas na batalha das ideias, das ruas e das cenas. Também continua lapidar a fórmula com que Dort caracteriza a empreitada brechtiana, uma súmula da questão: “Não instalar a História no palco, mas situar o palco e a plateia na História" (Dort, 1977, p. 375).

É a associação destas duas dimensões, a "dimensão política ontológica" e a "di- 
mensão histórica", que caracteriza um autêntico divisor de águas conceitual. Palco e plateia - hoje talvez seja melhor falar em eventos cênicos ou em experiências teatrais (a nomenclatura não é o essencial neste momento) - só fazem sentido na história e à luz da ação política. Ou ainda, não faz sentido indagar o teatro fora da história, e esta opção, assim como o próprio teatro, são sempre políticos.

A esta altura caberia a pergunta: toda esta argumentação para uma conclusão tão óbvia? Sim, nossa época - ingrata teoricamente - parece exigir o que seria evidente em outros momentos. A conclusão que tiramos não quer dizer que o ápice teatral tenha sido alcançado pelo gênio de Augsburgo, e que, portanto, de certa forma, a história teria acabado. Seria um contrassenso tamanho. O pulo do gato conceitual apenas indica que, no estágio atual do pensamento sobre o teatro e a sociedade, nada sugere que seja possível excluir as dimensões histórica e política enquanto fundamentos analíticos para a compreensão da complexidade deste binômio: teatro e sociedade. Reflexão que toma corpo pela primeira vez com Brecht. Assim, e a definição de Dort novamente é muito precisa, não é o distanciamento que é fundamental em Brecht, "que permanece uma técnica", mas "a organização de uma nova ordem de relações". Em outras palavras, Brecht propõe "a organização de uma nova dialética entre o palco, a plateia e a história" (Dort, 1977, p. 376).

Se o brechtismo é certamente mais do que isso, é, precisamente, a centralidade da história (e da ação política) que permite compreender algo que o ultrapassa (o brechtismo) como aventura do pensamento, escapando dos limites do próprio teatro brechtiano ou inspirado por ele. A centralidade da história é, portanto, o instrumento conceitual aplicável para refletir, inclusive, sobre o teatro que não propõe "uma nova ordem de relações", mas que, evidentemente, não está acocorado fora do mundo, flutuando feito bolha de sabão num mundo apolítico e ahistórico. Para quem vê o teatro de fora e está interessado em analisar o fenômeno teatral, a abordagem sócio -estética seria, portanto, a mais adequada. Para quem está dentro, Dort sugere:

Que hoje o teatro assuma sua vocação política. E se critique como teatro para nos permitir aceder à história.

Recusemos o dilema: particular ou geral, comédia ou tragédia. E invoquemos o geral apenas através do particular; evoquemos o particular somente em função do geral.

Uma dramaturgia do nosso tempo: aquela em que a descrição do cotidiano é ascensão para a História (Dort, 1986, p. 247)².

Outros autores indicaram caminhos semelhantes, em diversas latitudes e com diferentes colorações políticas. Para Eric Bentley, "a subversão, a rebelião, a revolução no teatro não são uma mera questão de programa, e muito menos podem ser definidas em termos de um gênero particular de peça" (1969, p. 178). O crítico norte-americano reconhecia no teatro, especialmente nos textos que escreveu a partir da segunda metade dos anos $1960^{3}$, a "vocação política" mencionada por Dort. Daí sua afirmação de que "existe certo grau de 'subversão' no próprio fenômeno teatral" (Bentley, 1969, p. 178). Confirma esta interpretação, por antítese, sua avaliação negativa da televisão (uma espécie de anti-ágora) e do cinema de Holywood, que

\footnotetext{
2 Em função de um erro de tradução ou de impressão da versão brasileira, optamos por traduzir o texto diretamente do original francês.

${ }^{3}$ A este respeito é útil comparar os textos "Os prós e contras do teatro político" (1960) e "O teatro engajado" (1966), que revelam uma transição na posição do autor, aproximando-se da visão que apresentamos neste artigo. (Bentley, 1969)
} 
para ele seria "contra a imaginação poética", além servir ao controle econômico ou à dominação espiritual de amplas parcelas da população (Bentley, 1991, p. 343 e 346 ).

No Brasil, Dias Gomes, pouco antes de sua imersão televisiva, sentenciou:

Em primeiro lugar, devemos levar em conta o caráter do ato político-social inerente a toda representação teatral. A convocação de um grupo de pessoas para assistir a outro grupo de pessoas na recriação de um aspecto da vida humana, é um ato social. E político, pois a simples escolha desse aspecto da vida humana, do tema apresentado, leva o autor a uma tomada de posição. Mesmo quando ele não tem consciência disso [...] Toda escolha importa em tomar partido, mesmo quando se pretende uma posição neutra, abstratamente fora dos problemas do jogo, pois o apoliticismo é uma forma de participação pela omissão. Pois esta favorece o mais forte ajudando a manter o status quo. Toda arte é, portanto, política" (Dias Gomes, 1968 , p. 10) ${ }^{4}$

Ele sabia do que estava falando. Pela mesma época, também no Brasil, Oduvaldo Vianna Filho se debruçava, prática e teoricamente, sobre a questão. Maria Sílvia Betti resume uma das conclusões a que chegou Vianinha:

Num contexto como este [pós-AI-5], o fundamental para Vianna não era debater a oposição entre racional versus irracional, ou entre consciente versus inconsciente, mas apontar a legitimidade da história como horizonte de trabalho e de representação (Betti, 2012, p. 193).

Portanto, continua Betti, "a contradição central que se apresentava para Vianna não era a observada entre o rígido racionalismo de um lado e a forma instintiva do outro, mas sim entre a historicidade e a não historicidade". Daí, por consequência, a defesa feita por Vianinha da centralidade da ação política, da inteligibilidade do mundo e da ideia que ele "pudesse ser objeto de transformação". (Betti, 2012, p. 193 e 194). A própria argumentação de Vianinha, em um famoso texto do final dos anos 1960 ("Um pouco de pessedismo não faz mal a ninguém"), classificando o teatro em três vertentes: "de esquerda", "esteticista" e "comercial" (Vianna, 1968), também precisaria ser rigorosamente compreendida sob a perspectiva histórica (incluindo, mas indo além das considerações tradicionais sobre a política de conciliação de classes do PCB), para dele se tirar não uma lição sobre o teatro (da época ou posterior), mas uma visão com ambição totalizante sobre o fenômeno teatral e os processos sociais, concordando-se ou não com ela.

Como seria de esperar, o vácuo deixado pela recusa da historicidade abria o terreno para toda sorte de devaneio, confusão e mistificação, tema que vamos explorar mais adiante. A análise de Vianinha, segundo a autora, ganha atualidade em função da "recusa epistemológica da historicidade" (Betti, 2012, p. 195), que seria uma das características da chamada cultura pós-moderna. O tema é mais complexo do que habitualmente se apresenta, uma vez que não há equivalência automática entre pós-moderno (Harvey, 1992; Jameson,1996; Eagleton, 1998) e pós-dramático, a não ser que se empreste a este último termo a definição (pós- moderna) de Hans-Thies Lehmann (2007). Eagleton, por exemplo, considera o pós- moderno "a ideologia de uma época histórica específica do Ocidente" (1998, p. 116), definição que admite nu-

${ }^{4}$ Dois dos autores citados, Eric Bentley e Dias Gomes, são mencionados por Kátia Paranhos no texto "Pelas bordas: História e teatro na obra de João das Neves", em Kátia Paranhos (org.). História, teatro e política, São Paulo: Boitempo, 2012, p. 135-156. 
ances, mas globalmente indica que o pós-moderno faz parte dos nossos problemas, ideia com a qual conclui o livro As ilusões do pós- modernismo. Já o pós-dramático pode designar outra coisa que a ideologia anti- brechtiana destilada pela obra e pela agenda política de Lehmann. Em outros termos, um hipotético teatro pós-dramático (na falta de melhor designação) pode ser muito mais do que uma mera convulsão caleidoscópica imagética, propositalmente desprovida de sentido, niilista, lúdica e cínica ${ }^{5}$. Este trabalho de (des)construção conceitual em torno da teoria do pós-dramático ainda precisa ser feito, será um benefício ao teatro contemporâneo que inova esteticamente sem dar sinal de abandonar sua ancoragem e sua ambição crítica.

Raymond Williams, ao analisar as duas grandes correntes do teatro de vanguarda, não hesita em considerá-las, cada qual a seu modo, "políticas", avaliando que as ações dos setores conservadores ou reacionários representam "políticas de uma avant-garde como uma arrière-garde". Para Williams tentar cancelar a realidade humana, racionalizando a derrota, ou aceitando como inevitável a miséria que é histórica, é também, e sempre, uma clara ação política. No vasto campo da "reação" estariam Artaud e Grotowski, assim como Eliot, Yeats, Claudel e Beckett, representantes de um teatro que "tem programaticamente reduzido a escala das possibilidades humanas e da ação humana, convertendo um dinamismo da forma que havia flertado com um dinamismo da ação numa condição de paralisia repetitiva e mutuamente equivocada." (Williams, 2011, p. 91-92). Embora o tema seja delicado, há diferença entre, por um lado, romper com os valores e as formas da burguesia e, por outro, construir uma alternativa real de sociedade:

[...] uma tendência estava se movendo para aquela nova forma de dissidência burguesa que, na sua própria ênfase na subjetividade, rejeitou o discurso de qualquer mundo público como algo irrelevante para as suas preocupações mais profundas. A liberação sexual, a emancipação do sonho e da fantasia, um novo interesse pela loucura como uma alternativa à sanidade repressiva e uma rejeição da linguagem ordenada como uma forma de dominação oculta, embora rotineira, todas essas preocupações eram vistas como a dissidência real, uma tendência que culminou no surrealismo e no "teatro da crueldade" de Artaud, rompendo tanto com a sociedade burguesa quanto com as formas de oposição a ela que haviam sido geradas dentro de seus termos. Por outro lado, a tendência oposta e mais política defendia a renúncia total da burguesia, com o propósito de passar da dissidência para a afiliação consciente à classe trabalhadora: o primeiro teatro soviético, Piscator e Toller e, por fim, Brecht.” (Williams, 2011, p. 82-83)

Ao analisar o surgimento e os impasses do naturalismo teatral, destacando a inadequação entre forma (o drama na "sala de estar" burguesa) e conteúdo (as crises econômicas e sociais), e o posterior desenvolvimento das vanguardas, Williams coloca a reflexão sobre o teatro moderno e contemporâneo sob o guarda- chuva da história e da ação política. Ele menciona, por exemplo - em oposição a uma tendência que podemos supor menos política -, uma tendência "mais política", e afirma que "o conceito de 'teatro político', por razões óbvias, está associado, sobretudo, com a segunda tendência. Mas seria errado ignorar por completo os efeitos políticos da

\footnotetext{
${ }^{5}$ Para uma apreciação crítica inicial do livro de Hans-Thies Lehmann, ver Sérgio de Carvalho, "Apresentação", em Teatro pós-dramático. São Paulo: Cosac Naify, 2007.
} 
primeira tendência" (2011, p. 83).

As opções pela esfera pública ou pelo subjetivismo, ou mesmo pela combinação mais ou menos feliz, mais ou menos possível, entre elas, dá régua e compasso para compreender aspectos decisivos do teatro dos nossos dias, embora o conjunto destas opções inscreva-se sempre, como estamos salientando, no campo da ação política.

\section{O SENTIDO PROFANO}

O debate anterior abre o caminho para aprofundar outro aspecto central. Vou citar uma citação na tentativa de esclarecê-lo. Trata-se de Josette Féral que cita Annette Michelson:

Existem na renovação dos modos de representação, dois movimentos de base divergentes que modelam e animam suas principais inovações. O primeiro, ancorado nos prolongamentos idealistas de um passado cristão, é mito-poético pelas suas aspirações, eclético pelas suas formas e constantemente atravessado pelo estilo dominante e polimorfo que constitui o vestígio mais tenaz do passado: o expressionismo. Os porta-palavras são: para o teatro, Artaud e Grotowski, para o cinema, Murnau e Brakhage, e para a dança, Wigman e Graham. O segundo, consequentemente profano no seu engajamento à objetificação, procede do cubismo e do construtivismo; suas abordagens são analíticas e seus porta-palavras são: para o teatro, Meierhold e Brecht, para o cinema, Eisenstein e Snow, e para a dança, Cunningham e Rainer. (Michelson, apud Féral, 1985, p. 125, 126)

Este resumo, embora insuficiente, tem o mérito de limpar o terreno. As distinções sumarizadas pela crítica de arte norte-americana não devem ser tomadas em termos de adesão ou repulsa absolutas. Ou isto ou aquilo. Não se trata de um flaflu passional. Também não se trata de um esquematismo démodé, ultrapassado por estudos culturais up to date. Estas distinções são antes balizas, oriundas da grande tradição europeia que formatou parcialmente o repertório cultural brasileiro. Entender quais são e onde se situam estas balizas nos permite ver mais nitidamente que ações (e opções) estão sendo feitas, política e historicamente, no campo do teatro e da sociedade.

As conclusões as quais chega Josette Féral no texto em que cita Michelson ("Performance et théâtralité: le sujet démystifié"), não são as nossas. A própria Féral revê e altera várias de suas conclusões em textos posteriores. É principalmente a discussão sobre o "sentido" que provoca clivagem. Para Féral, à época entusiasmada com as possibilidades da performance e admitindo uma distinção inequívoca entre esta e o teatro convencional, "a performance não visa a um sentido, mas ela faz sentido na medida em que trabalha precisamente nestes locais de articulação extremamente vagos [flous, no original] de onde acaba por emergir o sujeito" (Féral, 1985, p. 130). E na sequência do texto: "uma performance não quer dizer nada, [...] ela não visa a nenhum sentido preciso e único, mas [...] ela busca sobretudo revelar lugares de passagem, 'ritmos', diria Foreman, (trajetória do gesto, do corpo, da câmera, do olhar...) e assim despertando o corpo, do performer e do espectador, da anestesia ameaçadora que os assombra" (Féral, 1985, p. 131).

A polêmica aqui não é sobre a definição de performance, seria objeto para ou- 
tro artigo, mas a respeito da interpretação sobre o sentido, ou ausência dele, em manifestações teatrais e performáticas. Quando Féral afirma, e defende, que o primeiro objetivo da performance é o de "desfazer as 'competências' (teatrais essencialmente)", supõe-se que uma destas competências, para ela, seja a capacidade do teatro em extrair ou criar sentidos a partir da realidade. Abdicar do "sentido", sob as mais diversas alegações, é um sinal clássico de falência do pensamento, ou estratégia diversionista, indissociável de injunções políticas e históricas precisas, sejam elas conhecidas ou não, assumidas ou não, por aqueles que abdicam. Portanto, merece destaque e análise o deslumbre (ou fetiche) com a recusa do "sentido". ${ }^{6}$ E esta análise só pode ser feita considerando a época que induz, permite, autoriza, viabiliza, enquadra, formata... este ressurgimento e valorização do irracionalismo. Como toda forma de teorização carrega conteúdos políticos (e ideológicos), também o irracionalismo contemporâneo - na versão místico-kitsch ou envolvendo aporias pretensamente profundas - faz parte, querendo ou não, das lutas pela interpretação e pelo controle do mundo social. Opõem-se uma visão idealista e uma visão profana de mundo, para retomar os termos de Michelson. Grande parte do debate sobre o pós-moderno e, no âmbito teatral, do pós-dramático (segundo a terminologia proposta, ou sequestrada, por Hans-Thies Lehmann) depende da compreensão fina desta oposição de modelos. E depende, também, das disputas políticas (apresentadas, muitas vezes, como meros embates intelectuais ou estéticos) bastante concretas sobre o tipo de mundo em que queremos viver.

Encerrando uma palestra em São Paulo, o dramaturgo, poeta e ensaísta britânico Edward Bond afirmou que "cabe a nós fazer com que a forma de vida e pensamento atual não contribua para piorar as coisas". E concluiu, distante de qualquer romantismo ou ingenuidade sugeridos pela frase, que "este é o trabalho de que o teatro deveria se incumbir: tornar todos os seres humanos mais felizes" (Bond, 2004, p. 242). Podemos ressalvar que a felicidade implica em autonomia, exige igualdade e que seria preciso definir melhor os termos ("felicidade", por exemplo, lembrando da Política de Aristóteles). Mas seria injusto negar que, finalmente, é disso mesmo que se trata: felicidade para todos.

É o caso de ver nesta frase de Bond, coerente com uma visão de mundo decididamente não idealista, mais uma aposta (embora inferida pela realidade) do que uma certeza teleológica ou o resultado de um dogmatismo político qualquer. Nesta concepção, a história é um campo de possíveis (não o resultado de leis conhecidas, imutáveis e implacáveis) em que a luta (às vezes revolucionária) está sempre presente - porque é impossível fazer a economia do embate social ou subtrair a razão e a política dos processos sociais -, mas cujo desfecho é sempre imprevisível.7 A trajetória artística e política de Edward Bond é o exercício desta maneira de conceber o mundo e o teatro, assim como sua maneira de ver o mundo e o teatro resultam de sua práxis artística e política como criador e intelectual.

\footnotetext{
${ }^{6}$ Uma versão bem brasileira deste fenômeno ficou conhecida como "desbunde". Ver, por exemplo, Heloísa Buarque de Hollanda. Impressões de Viagem: CPC, Vanguarda e desbunde. 1960/1970. Rio de Janeiro: Aeroplano. 2004. O livro, escrito no final dos anos 1970, não está isento de problemas, mas vale como retrato de época e pelos excelentes anexos.

${ }^{7}$ Ver Le pari mélancolique [A aposta melancólica], de Daniel Bensaïd, Paris: Fayard, 1997.
} 


\section{DISFARCES E CULATRA}

Mencionados estes aspectos, presença inescapável da dimensão histórico- política no fenômeno teatral e reivindicação da inteligibilidade (produção crítica de sentido), pode-se analisar aspectos da relação arte/sociedade, cultura/política, que embora particulares têm ressonância nas manifestações teatrais contemporâneas. Um destes aspectos é o travestimento, ou os disfarces, que acabam por nublar a apreensão crítica. Como são menos evidentes (caso contrário não seriam disfarces) e, portanto, menos sujeitos à detecção e à crítica, estes disfarces funcionam como estratégias ideológicas (de controle social, de fabricação do consenso etc.) cujo alcance, evidentemente, atinge o teatro, e são utilizados inclusive por alguns que imaginam combater o establishment.

Uma explicação para este fato estaria nos anacronismos. Expedientes outrora críticos e eficientes socialmente são anulados em novos contextos. Roberto Schwarz chamou a atenção para a recuperação pela publicidade de técnicas desenvolvidas por Brecht, exemplificando com o distanciamento "brechtiano" do ator que protagonizou durante anos as conhecidas propagandas da palha de aço Bombril. Schwarz também mostrou como o foco "brechtiano" na "infra-estrutura material da ideologia" é praticado por qualquer telejornal mediano quando revela os bastidores da cena, deixando à mostra câmeras, cabos e operadores (Schwarz, 1999, p. 130). O mesmo vale para outros instrumentos, expedientes e procedimentos utilizados pela tradição teatral crítica (iluminação da plateia, apartes, songs, exposição comentada da fábula, distanciamento entre personagem e ator e deste com o público, cartazes nomeando as cenas etc.).

Operações críticas, potencialmente reveladoras de relações sociais complexas, são postas de pernas para o ar, os sinais são trocados e a crítica (do fetiche, do mercado, do consumo, do luxo, do individualismo...) pode transformar-se em apologia. Ou seja, e este é um caso clássico, aspectos formais utilizados na crítica da forma-mercadoria passam a servir como alavancas para o consumo conspícuo e para a aceitação da lógica mercantil. Aniquilar a empatia, usar parábolas, "estranhar" ou "distanciar", podem ser largamente insuficientes se o "método" brechtiano não estiver presente ${ }^{8}$. E ele está ausente não apenas na publicidade, nos telejornais ou nas telenovelas, mas também em determinados filmes cults, em múltiplas manifestações artístico-performáticas hiper ou pós- modernas, e até mesmo em parte do bem-intencionado teatro crítico.

É por isso que importantes achados estéticos dos anos 1960 (do Arena, Oficina, Opinião, CPC's, mas também do Cinema Novo e da MPB) - desconsiderando, para efeito de análise, "a gelatina do nacionalismo populista" (Schwarz, 1999, p. 122) que não poupou o teatro, o cinema e a música da época -, também correm o risco de não funcionar nos dias de hoje. Como um tiro que sai pela culatra, podem produzir uma desastrosa inversão do sentido crítico original. Já na época em que foram criados, pi-

\footnotetext{
8 "É tentador sugerir que precisamente a conhecida sagacidade de Brecht seja o seu método ou mesmo sua dialética: a inversão das hierarquias de um problema, a premissa maior tornando-se a menor, a absoluta tornando-se a relativa, a forma tornando-se o conteúdo e vice-versa - são todas operações em que o dilema em questão é virado do avesso, e uma linha de ataque inesperada e imprevisível se abre sem levar nem para o beco sem saída do insolúvel nem para a banalidade da doxa estereotipada sobre o assunto." (Jameson, 2013, p. 47)
} 
pocavam as contradições. Para Schwarz "a utilização dos procedimentos narrativos, concebida originalmente para propiciar a distância crítica, nalguns momentos via-se transformada por Boal e Glauber no seu contrário, em veículo de emoções nacionais, 'de epopeia', para fazer contrapelo à derrota política" (Schwarz, 1999, p. 122).

O golpe de 1964 e o tiro de misericórdia do Al-5, quatro anos depois, praticamente interromperam o avanço social e a experimentação estética que estavam em curso acelerado desde meados da década anterior. E foi uma dupla interrupção: imediata, física, concreta, porque a produção artística definhou sob os coturnos da repressão e da censura (especialmente depois de 1968); e interrupção do pensamento, pela incapacidade de toda uma geração em medir e interrogar as inovações formais na construção social objetiva. Embora não se possa ignorar a migração de artistas e coletivos teatrais para práticas menos institucionalizadas, resumidas pelas fórmulas "teatro popular", "comunitário", "amador" ou "independente". Não é casual que o 1 Seminário de Teatro Popular tenha sido realizado na cidade de São Paulo em 1974, coincidindo com o final do governo Médici, auge da repressão e do terrorismo de Estado.

Não pode passar em branco o fato de que Terra em transe de Glauber Rocha, parte do tropicalismo (na música, nas artes plásticas e na literatura) e da produção do Teatro Oficina (d'O Rei da Vela em diante), deram exemplos de confusão ou evidente renúncia do pensamento crítico. Por isso Roberto Schwarz não poupa as experiências dionisíacas e ritualizantes de Zé Celso, mencionando "uma espécie de colapso histérico e histórico da razão." (Schwarz, 1999, p. 124). A carta que o Grupo Oficina envia a Sábato Magaldi em 1972 (Arte em Revista, 1983, p. 51-55), escrita por Zé Celso, confirma, além do "desespero irracional" apontado pelo crítico, o viés autoritário do grupo (além de neorromântico e protomessiânico), que entre neologismos duvidosos ("re-volição" ou "te-ato") distribui ataques pouco consistentes e ofensas a Magaldi e a Anatol Rosenfeld. Até Galileu é convocado para cerrar fileiras com a sensorialidade e a "viagem" propostas por Gracias Señor (a montagem criticada por Sábato Magaldi). Novamente, não se trata de fla-flu. Não é o caso de comprar o pacote integral de uma crítica que, sem dúvida, também exerceu papel normalizador, recusando experiências radicais que não se enquadravam na sua grade analítica. A pior das armadilhas é aquela que exige falsas escolhas. Está viva na memória a falácia, vendida por boa parte da mídia mundial, que nos queria aprisionar na escolha entre George W. Bush e Bin Laden, ou seja, entre a nova etapa do hegemonismo norte-americano (com tintas de fundamentalismo protestante) e o terrorismo patrocinado pela ditadura saudita.

Discursos e práticas, no âmbito social ampliado ou no especificamente teatral, uma vez disfarçados com roupas aparentemente críticas, podem se prestar aos piores serviços, ou, na melhor das hipóteses, servir esquizofrenicamente a dois amos. É preciso reconhecer, saindo do conforto, que obviamente nem todas as escolhas são falaciosas, e portanto opções precisam ser feitas. Não se pode ter a manteiga e o dinheiro da manteiga, diz um conhecido provérbio francês. 


\section{SE NÃO FOR STAROUP, PROTESTE}

Se parte da herança brechtiana e do teatro dos anos 1960 - ela mesma já tendo se reapropriado da herança de Brecht -, não nos são mais socialmente úteis, o fato apenas confirma uma concepção do marxismo... e do brechtismo: o mundo só pode ser entendido historicamente e em transformação. E mais, as próprias categorias empregadas na análise do seu caráter histórico e transformável precisam ser, elas também, igualmente historicizadas. A tarefa não é fácil, mas é estimulante. Nós mesmos, em Teatro/mercadoria \#1, trabalho cênico criado em $1996^{\circ}$, tentamos dar uma forma capaz de revelar a recuperação feita pelo status quo capitalista da crítica antissistêmica. Para não glosar sobre trabalho próprio, aqui vai a análise de Iná Camargo Costa sobre dois momentos desta peça:

Uma cena do Woyzeck [incluída e retrabalhada em Teatro/mercadoria \#1] é uma aula minuciosa sobre o modo como o repertório realista dramático pode destruir uma cena épica. Mas o maior feito do espetáculo consiste na atualização do método cinematográfico de Guy Debord: desenvolvendo, sem enunciar, a tese debord-benjaminiana de que o espetáculo [no sentido que emprega Debord] tem a capacidade de transformar até mesmo as lutas revolucionárias (depois de derrotadas, é claro) em mercadoria, é apresentada, sem comentários, por desnecessários, a longa peça publicitária em que as lutas dos anos 1970 contra a ditadura foram transformadas em argumentos para demonstrar a qualidade e a resistência de uma determinada marca de jeans (Costa, 2008, p. 118).

Na mesma tela, lado a lado, apresentávamos o filme publicitário da Staroup, Passeata, produzido pela W/Brasil em 1988, e imagens documentais de protestos dos anos 1960. Não parece ter escapado ao júri do Festival de Publicidade de Cannes a qualidade - publicitária e política - do material criado por Washington Olivetto e Nizan Guanaes, atribuindo a ele o Leão de Ouro. O cinismo e o oportunismo eram mais uma vez premiados. Cannes percebeu que a transição para a democracia liberal - na época vivíamos sob o governo Sarney - era a prova dos nove de que a ditadura tinha vencido ${ }^{10}$. O mercado, enfim, podia ter livre curso. A rebeldia e em alguns casos o ímpeto revolucionário tinham cedido o lugar (ao preço que se sabe) para a calmaria (selvagem) da normalização capitalista. "Se não for Staroup, proteste", era o slogam da campanha.

A rudeza - e a eficiência - do massacre ideológico e midiático no Brasil é de tal magnitude, que nos pareceu necessário, à época, justapor os dois filmes, imaginando que a simples exposição do filme publicitário, mesmo no contexto de uma peça teatral crítica como Teatro/mercadoria \#1, fosse insuficientemente compreendida por uma parte importante dos interlocutores do trabalho. Nesta montagem, tanto como agora, estavam postas antigas e decisivas questões: Como ativar o pensamento crítico? Como identificar questões prioritárias e urgentes que merecem tratamento teatral? Como encontrar formas para examinar estas questões? Como dialogar produtivamente com o público, evitando, por um lado, as armadilhas da lição pronta e, de outro, a recusa do sentido? Como fugir dos standards estéticos e do formalismo

\footnotetext{
${ }^{9}$ Teatro/mercadoria \#1, montagem da Kiwi Companhia de Teatro, dirigida por Fernando Kinas, estreou no Sesc Copacabana em dezembro de 2006

${ }^{10} \mathrm{~A}$ este respeito vale a pena conferir o livro O que resta da ditadura, organizado por Edson Teles e Vladimir Safatle, São Paulo: Boitempo, 2010.
} 
estéril? Como plasmar, crítica e criativamente, conteúdos não hegemônicos e formas sensíveis? Como criticar a forma-mercadoria a partir do mundo do capital? Como expressar a rebeldia sem a complacência tão ao gosto das classes médias?

Com estas indagações vinham outras, aparentemente extrateatrais. Que modo de produção seria compatível com este tipo de teatro? Colaborativo, compartilhado, horizontal, associativo, não mercantil, cooperativado? Por último, mas não menos importante, quem são nossos interlocutores? Isto é, existe, e onde estará, o público capaz de reivindicar um teatro com estas características?

Somente dez anos depois de Teatro/mercadoria \#1 houve ocasião para rever este filme publicitário em um outro trabalho cênico. A montagem colombiana de Notas de cocina, escrita por Rodrigo Garcia e dirigida pelo espanhol Marc Caellas, confirma parcialmente a tese da recuperação de materiais ou dispositivos críticos pelo status quo. Uma recuperação, digamos assim, elevada ao quadrado, já que a matéria original (a rebeldia e o protesto da juventude), recuperada pela marca de jeans e pela agência publicitária, prestava-se à nova recuperação, desta vez por uma produção teatral relativamente rebelde, fazendo parte de um circuito artístico relativamente crítico, assistida por públicos relativamente interessados no protesto. Tudo muito relativo, como se vê.

Ao público, aos críticos, aos artistas, aos estudiosos, cabe reconhecer e fazer a adequada apreciação destes mecanismos, avaliando seus alcances e limites. Desfetichizar e dasalienar não saíram de moda.

\section{ABORDAGEM SÓCIO-ESTÉTICA}

Para destacar o aspecto geral das relações entre arte e história, teatro e sociedade, vale reforçar uma argumentação desenvolvida em outro artigo, com algumas novas ponderações (Kinas, 2013b).

Provavelmente há mais do que um fluxo de duas mãos entre o fenômeno teatral e o "campo histórico das relações humanas" (Brecht, 1979, p. 24). A abordagem não deve ser em termos de rígida dualidade, mas de "totalidade sócio- estética". Um exemplo de aplicação desta abordagem é o da correspondência entre o teatro brasileiro produzido nos anos 1960 e o contexto social e político vivido pelo país. As reflexões de Augusto Boal (representativas do Teatro de Arena), do ISEB (Instituto Superior de Estudos Brasileiros) e do PCB (e também de certos movimentos sociais, sindicais e estudantis) estavam em "perfeita sintonia", como destaca Edélcio Mostaço (1982, p. 45). Talvez se possa acrescentar que não se tratava propriamente de "sintonia", como se estivessem face a face dois campos autônomos (teatro e política), mas, justamente, de uma totalidade sócio-estética, já que as manifestações teatrais e políticas só podem ser compreendidas a partir do contexto em que se efetivam. É a démarche que adota Marcelo Ridenti ao analisar o mesmo período: "ficava mais uma vez evidente - como em geral ocorre com mais transparência nos momentos de impasses

\footnotetext{
4 "In Diderot's writings on painting and drama the object-beholder relationship as such, the very condition of spectatordom, stands indicted as theatrical, a médium of dislocation and estrangement rather than of absorption, sympathy, self-transcendence; and the success of both arts, in fact their continued functioning as major expressions of the human spirit, are held to depend upon whether or not painter and dramatist are able to undo that state of affairs, to detheatricalize beholding and so make it once again a mode of access to truth and conviction, albeit a truth and a conviction that cannot be entirely equated with any known or experienced before".
} 
na sociedade - que a produção cultural é ao mesmo tempo política, e vice-versa, ainda que nem sempre seja possível estabelecer precisamente a articulação entre arte e vida sócio-política" (Ridenti, 2000, p. 280).

Exemplos inequívocos da unidade sócio-estética foram as experiências realizadas em torno da revolução de 1917 (Meierhold, Maiakovski, Tairov, construtivismo, biomecânica etc.) e a efervescência da República de Weimar (Piscator, Toller, Brecht, teatro documentário, cabaré político etc.).

Evidentemente, a percepção do fenômeno sócio-estético é mais visível nos períodos de grande inquietação política e artística. Mais desafiador é identificar o fenômeno em tempos não tão intensos, quando os processos históricos e a produção artística e cultural parecem relativamente autônomos. É preciso destacar, ainda, que processos reativos, como o surgimento de um teatro conservador ou reacionário em tempos de contestação política, não desautorizam, antes confirmam a hipótese aqui apresentada. O conceito de backlash (utilizado por setores do movimento feminista) ajuda a explicar este fenômeno. Ele significa, basicamente, uma reação conservadora, com diferentes graus de violência, em resposta a avanços políticos conquistados por movimentos sociais.

Peter Bürger em Teoria da Vanguarda mostrou as complexas conexões entre o desenvolvimento (emancipação) da arte em relação aos desenvolvimentos tecnológicos, especialmente a partir das reflexões seminais de Walter Benjamin (1985). Para Bürger era fundamental evitar os esquematismos:

\footnotetext{
Ora, a emancipação é um processo que pode ser efetivamente promovido por meio do desenvolvimento das forças produtivas, na medida em que estas preparam um campo de novas possibilidades disponíveis para a concretização de necessidades humanas, mas isso não pode ser pensado independentemente da consciência humana. Uma emancipação que se impusesse natural e espontaneamente seria o contrário da emancipação (Bürger, 2008, p. 70).
}

A transposição do esquema marxista que relaciona o desenvolvimento das forças produtivas com a alteração substancial das relações de produção não pode ser aplicada mecanicamente ao conjunto arte/sociedade. Não basta que haja alteração da situação social (como o desenvolvimento de novas técnicas de reprodução), para que a situação artística (o sistema de arte e as obras ou processos) seja automaticamente alterada. $O$ "desenvolvimento técnico não deve ser interpretado como variável independente, sendo ele próprio dependente do desenvolvimento do todo social", diz Bürger, acrescentando que "não se deve atribuir unicamente ao desenvolvimento dos procedimentos técnicos de reprodução a ruptura decisiva no desenvolvimento da arte na sociedade burguesa" (Bürger, 2008, p. 70). Seria necessário levar em conta tanto uma relativa autonomia da vontade humana (a atitude política em ação), como a nova divisão do trabalho que se estabelecia neste tipo de sociedade, responsável pela especialização generalizada das ocupações, incluindo as artísticas.

Para Bürger, nem mesmo o surgimento e a generalização do mercado podem ser considerados como causas unívocas ou definidoras do processo de reconfiguração das artes. "O processo contraditório do surgimento da esfera social que designamos como arte, que (sempre pressionado por movimentos contrários) por séculos 
se prolongou, não pode ser deduzido de uma só 'causa', ainda que seja de tão central importância para o todo social como o mecanismo de mercado" (Bürger, 2008, p. 87).

Mais do que afirmar uma "vinculação" entre processos artísticos e condições sociais e históricas gerais, talvez seja o caso de pensar, como esboçado acima, em termos de unidade ou totalidade estético-social, em que a especificidade da esfera estética se objetifica em determinado contexto social. Mesmo que muitas vezes nosso vocabulário seja enganoso, ao nos referirmos, por exemplo, à "influência social" na criação artística, o sentido geral da reflexão tende a ser não dogmático, procurando dar conta da multiplicidade do real em sua sofisticada arquitetura histórica, política, social e estética. Ismail Xavier, na tentativa de compreender a produção cultural brasileira, empreende análise na mesma direção:

Certo momento do capitalismo e da evolução da técnica que organiza a vida cotidiana engendra ou, pelo menos, favorece um estilo de representação que se mostra capaz de dar conta da experiência histórica; quando as coisas mudam, quando a ordem econômica e o aparato técnico vão dando cada vez menos sinais visíveis de sua lógica, é necessário outra forma de arte para falar desse mundo e de suas determinações, seu sentido, sua maneira de condicionar, moldar, excluir. (Xavier, 2000, p. 108)

É o esforço dialético que merece ser retido como procedimento metodológico. Situações, ou momentos, sociais permitem, ou favorecem, expressões artísticas e estas são capazes de expressar a realidade. Quando a realidade se altera, e a lógica estabelecida entra em crise, outras formas artísticas são necessárias, e são capazes, por sua vez, de expressar esta nova realidade. As formas artísticas, no entanto, são também indutoras - na dimensão que cabe identificar em cada caso concreto - das determinações e condicionamentos que formatam o conjunto da experiência histórica.

\section{O CHÃO DA HISTÓRIA}

Não seria simples trazer o conjunto da argumentação feita até aqui para o chão da atualidade teatral brasileira. A reflexão que apresentamos está mais próxima de um elogio do método, à moda de Descartes, do que dos estudos de caso. É possível, no entanto, afirmar que uma experiência localizada e recente, a do teatro paulistano, especialmente após meados da década de 1990, apresenta elementos visíveis do que tentamos analisar. Visíveis, porque as ações do teatro de grupo, da articulação de artistas, coletivos e intelectuais (primeiro no Arte contra a Barbárie, depois no movimento 27 de Março e em torno do teatro de rua), e os resultados do Programa de Fomento ao Teatro para a cidade de São Paulo (em funcionamento desde 2002), têm sido objeto de investigação atenta, revelando uma imensa diversidade de práticas artísticas e sociais que expressam, e muitas vezes reivindicam, um protagonismo - ele também artístico e social - que há muitas décadas não se via ${ }^{11}$.

O atual teatro de grupo paulistano é, portanto, um concentrado, rico e contraditório, desta incrível dialética entre processos sociais e formas sensíveis. 


\section{Referências}

BENJAMIN, Walter. "A obra de arte na era de sua reprodutibilidade técnica". Trad. Sergio Paulo Rouanet. Em Magia e técnica, arte e política. Obras escolhidas I, São Paulo: Brasiliense, 1985.

BENSAÏD, Daniel. Le pari mélancholique. Paris: Fayard, 1997.

BENTLEY, Eric. O dramaturgo como pensador. Trad. Ana Z. Campos. Rio de Janeiro:

Civilização Brasileira, 1991. O teatro engajado. Trad. Yan Michalski. Rio de Janeiro: Zahar, 1969.

BETTI, Maria Sílvia. "O corpo a corpo de um dramaturgo em tempos sombrios: concepções dramatúrgicas no trabalho de Oduvaldo Vianna Filho na fase pós -AI-5". Em PARANHOS, Kátia (org.). História, teatro e política, São Paulo: Boitem po, 2012, p. 181-199.

BOND, Edward. "Considerações sobre o teatro atual". Em O teatro e a cidade. São Paulo: Secretaria Municipal de Cultura, 2004, p. 235-242.

BRECHT, Bertolt. Écrits sur le théâtre, v. 2. Trad. Jean Tailleur e Edith Winkler. Paris: Arche, 1979.

BÜRGER, Peter. Teoria da vanguarda. Trad. José Pedro Antunes. São Paulo: Co sac Naify, 2008.

COSTA, Iná Camargo. A luta dos grupos teatrais de São Paulo por políticas públi cas para a cultura. São Paulo: Cooperativa Paulista de Teatro, 1998.

. "Teatro de grupo contra o deserto do mercado". Em ArtCultura, Uberlândia, v. 9, n. 15, p. 17-29, jul.-dez. 2007.

DESGRANGES, F., LEPIQUE, M. Teatro e vida pública. O Fomento e os coletivos teatrais de São Paulo. São Paulo: Hucitec, 2012.

DIAS GOMES. "O engajamento é uma prática de liberdade". Em Revista Civiliza ção Brasileira, no 2, 1968, p. 7-17.

DORT, Bernard. O teatro e sua realidade. Trad. Fernando Peixoto. São Paulo: Perspectiva, 1977. Théâtres. Paris: Seuil (Collection Points), 1986.

\footnotetext{
${ }^{11}$ Ver, por exemplo: Iná Camargo Costa, "Teatro de grupo contra o deserto do mercado". Em ArtCultura, Uberlândia, v. 9, n. 15, p. 17-29, jul.-dez. 2007, e da mesma autora (org.) A luta dos grupos teatrais de São Paulo por políticas públicas para a cultura. São Paulo, Cooperativa Paulista de Teatro, 1998; Fernando Kinas, "A lei de fomento ao teatro para a cidade de São Paulo: uma experiência de politica pública bem sucedida". Revista Extraprensa, São Paulo, v.1, 2010, p. 194-203. Este texto, revisado e aumentado, foi publicado no Caderno de Estudos Contrapelo, São Paulo (Kiwi Companhia de Teatro), v. 2, 2015, p. 62-69, com o título "O tormento necessário. A Lei de Fomento no olho do furacão"; Flávio Desgranges e Maysa Lepique (orgs.), Teatro e vida pública. O Fomento e os coletivos teatrais de São Paulo. São Paulo, Hucitec, 2012 e Carlos Gomes e Marisabel de Mello (orgs.), Fomento ao Teatro. 12 anos. São Paulo, Secretaria Municipal de Cultura, 2014.
} 
EAGLETON, Terry. As ilusões do pós-modernismo. Trad. Elisabeth Barbosa. Rio de Janeiro: Jorge Zahar, 1998.

FÉRAL, J., SAVONA, J. L., WALKER, E. A. (orgs.). Théâtralité, écriture et mise en scène. Québec: Hurtubise, 1985.

GOMES, C. A. M., MELLO, M. L. Fomento ao Teatro. 12 anos. São Paulo: Secreta ria Municipal de Cultura, 2014.

GRUPO OFICINA. "Carta aberta ao Sábato Magaldi". Em Arte em revista, no 2, 1983 (2 edição). São Paulo: CEAC-ECA-USP, p. 51-55.

HOLLANDA. Heloísa Buarque de. Impressões de Viagem: CPC, Vanguarda e des bunde. 1960/1970. Rio de Janeiro: Aeroplano. 2004.

JAMESON, FREDRIC. Pós-modernismo: a lógica cultural do capitalismo tardio. Trad. Maria Elisa Cevasco. São Paulo: Ática, 1996.

Brecht e a questão do método. Trad. Maria Sílvia Betti. São Paulo: Cosac Naify, 2013.

HARVEY, David. Condição pós-moderna: uma pesquisa sobre as origens da mu dança cultural. Trad. Adail Sobral e Maria Gonçalves. São Paulo: Loyola, 1993.

KINAS, Fernando. "Teatro, verdade e poder". Em Aparte XXI, Revista do Teatro da Universidade de São Paulo, no 6, p. 29-38, 2013a.

"O gosto pelo real no teatro contemporâneo". Em Sala Preta, Revista da Uni versidade de São Paulo, v. 13, n 2, p. 144-154, 2013 b.

"A Lei de Fomento ao teatro para a cidade de São Paulo: uma experiência de politica pública bem sucedida". Revista Extraprensa, São Paulo, v.1, 2010, p. 194-203.

"O tormento necessário. A Lei de Fomento ao teatro para a cidade de São Paulo". Caderno de Estudos Contrapelo, São Paulo, v.2, 2015, p. 62-69.

LEHMANN, Hans-Thies. Teatro pós-dramático. Trad. Pedro Süssekind. "Apresen tação" de Sérgio de Carvalho. São Paulo: Cosac Naify, 2007.

PARANHOS, Kátia. "Pelas bordas: História e Teatro na obra de João das Neves". Em PARANHOS, Kátia (org.). História, teatro e política, São Paulo: Boitempo, 2012, p. 135-156.

RIDENTI, Marcelo. Em busca do povo brasileiro: artistas da revolução, do CPC à era da TV. Rio de Janeiro: Record, 2000. 
SCHWARZ, Roberto. Sequências brasileiras. São Paulo: Companhia das Letras, 1999. TELES, E. e SAFATLE, V. (orgs.). O que resta da ditadura. São Paulo: Boitem po, 2010.

VIANNA FILHO, Oduvaldo. "Um pouco de pessedismo não faz mal a ninguém". Em Revista Civilização Brasileira, Caderno Especial, n² 2, julho 1968, Rio de Ja neiro, p. 68-75.

WILLIAMS, Raymond. Política do modernismo. Trad. André Glaser. São Paulo: Unesp, 2011.

XAVIER, Ismail. "O cinema brasileiro dos anos 90" (entrevista). Em Praga, no 9. São Paulo: Hucitec, 2000, p. 97-138.

Recebido em: 02/05/2016 Aprovado em: 02/07/2016 